\title{
Loss of Body Weight Accompanying Cellular Brain Edema Induced by Water Intoxication in the Rat
}

\author{
P. KOZLER ${ }^{1}$, D. MAREŠOVÁ ${ }^{1}$, J. POKORNÝ $^{1}$ \\ ${ }^{1}$ Institute of Physiology, First Faculty of Medicine, Charles University, Prague, Czech Republic
}

Received November 5, 2018

Accepted November 23, 2018

Epub Ahead of Print January 10, 2019

\begin{abstract}
Summary
Induction of cellular cerebral edema (CE) was achieved by a standard method of water intoxication which consisted of fractionated intraperitoneal administration of distilled water (DW) together with the injection of desmopressin (DP). Using metabolic cage, fluid and food balance was studied in two groups of eight animals: group C - control; group CE - cellular edema induced by water intoxication. For each rat the intake (food pellets and water) and excretion (solid excrements and urine) were recorded for $48 \mathrm{~h}$ together with the initial and final body weight. CE animals consumed significantly less food, drank less water and eliminated the smallest amount of excrements. The induction of cellular cerebral edema was accompanied with a significant loss of body weight (representing on average $13 \%$ of the initial values) mainly due to a reduction of food intake. This phenomenon has not yet been reported.
\end{abstract}

\section{Key words}

Weight loss $\bullet$ Water intoxication $\bullet$ Brain edema

\section{Corresponding author}

J. Pokorný, Institute of Physiology, First Faculty of Medicine, Charles University, Albertov 5, 12800 Prague 2, Czech Republic. E-mail: pokorny@lf1.cuni.cz

Brain edema can develop after almost any insult to the brain, including trauma, infarction, neoplasm, or abscess, as well as conditions such as hypoxia, or toxic or metabolic perturbation. In edema, the expanding volume causes increasing pressure, resulting in intracranial hypertension. This life-threatening condition has high rates of mortality in such clinical pathologies, such as stroke and traumatic brain injury, where there's no causal management known at present. The prevailing cause of intracranial hypertension in both above-mentioned pathologies is cellular edema (CE) (Ayata and Ropper 2002, Kimelberg 1995, Kimlberg 2004, Liang et al. 2007, Marmarou 2007, Rhoney and Parker 2006).

For studying the pathophysiology of cerebral edema in experimental models, water intoxication is often used (Manley et al. 2000, Silver et al. 1999, Yamaguchi et al. 1997, Yamaguchi et al. 1994, Wasterlain and Posner 1968, Papadopoulos and Verkman 2007, Oztaş et al. 2000, Plangger and Völkl 1989). We have also been using this method in our experiments (Kozler et al. 2017a, Kozler and Pokorný 2012, Kozler and Pokorný 2014, Kozler et al. 2013, Marešová et al. 2014). In previous studies we found that during the period between the beginning of water intoxication and the experimental analysis, the animals lost their body weight, in average of $13 \%$ of their initial weight. This finding was constant in all our experiments (in more than 100 rats). The aim of this study was to highlight this phenomenon which was not mentioned by other authors, who used the same experimental method of induction of cellular edema in rats. We analyzed in detail the water and food intake and the excretion of solid excrements and urine in the control and cerebral edema induced rats

For the experiment, adult male rats of the Wistar strain were used and treated in accordance with the current Guidelines for the Treatment of Laboratory Animals (EU Guidelines 86/609/EEC). 

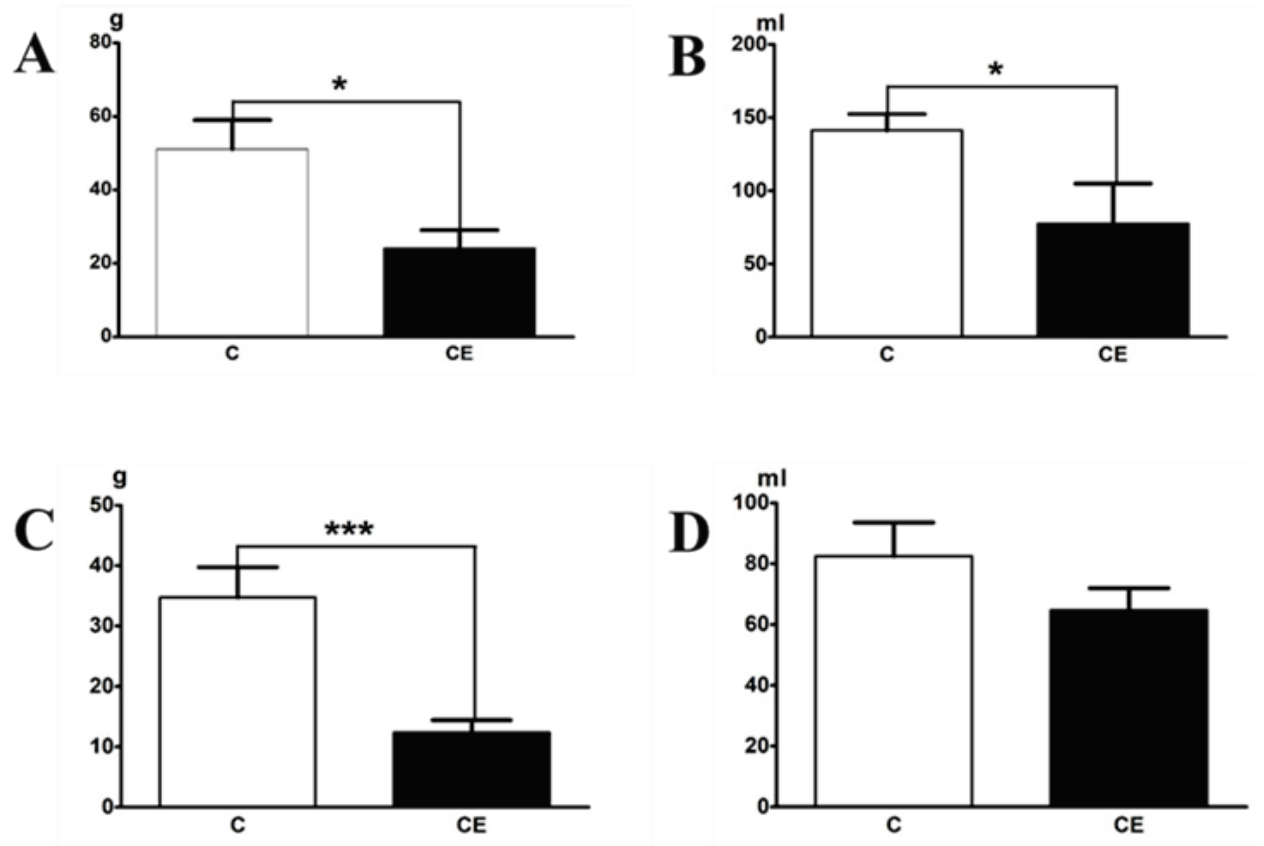

Fig. 1. Parameters studied in the control group $(C$, white columns) and in the group of rats with cellular edema (CE, black columns): A. food intake $(\mathrm{g} / 48 \mathrm{~h})$, B. peroral water intake $(\mathrm{ml} / 48 \mathrm{~h})$, C. solid excrements $(\mathrm{g} / 48 \mathrm{~h})$, and D. urine excretion $(\mathrm{ml} / 48 \mathrm{~h})$. Data are means \pm SEM, significant differences between $\mathrm{C}$ and $\mathrm{CE}$ groups are indicated as * $\mathrm{p}<0.05$, $* * * \mathrm{p}<0.001$.
Cellular edema was induced by water intoxication, i.e. injecting distilled water in a total amount corresponding to $20 \%$ of body weight intraperitoneally (i.p.) in three consecutive doses over $24 \mathrm{~h}$ with a simultaneous administration of desmopressin. Each sub-dose represented one-third of the total dose of $0.032 \mathrm{mg} / \mathrm{kg}$ desmopressin (1-desamino-8-D-arginine vasopressin) (OCTOSTIM $\AA$, Ferring). Desmopressin is an agonist of vasopressin $V_{2}$ receptors the antidiuretic effects of which potentiate the effect of hyperhydration by inducing hyponatremia (Manley et al.2000, Silver et al. 1999, Yamaguchi et al. 1997).

Metabolic studies were performed in rats placed in metabolic cages (Metabolics TM, Biological Monitoring) for $48 \mathrm{~h}$, which allowed the accurate measurement of food and fluid intake as well as urine and feces excretion. All rats in metabolic cages had free access to food and water ad libitum. For each rat we recorded the amount consumed food pellets and water along with the measurement of excreted solid wastes and urine. The experiment consisted of 16 rats divided into two groups of eight animals: group $\mathrm{C}$ - control, intact rats, and group $\mathrm{CE}$ - rats with standard $\mathrm{CE}$ induction by water intoxication.

The results of all measurements were statistically evaluated using the GraphPad Prism program (parametric ANOVA and nonparametric Kruskal-Wallis test; statistical significance was set at $5 \%$ ).

Our results have shown that the rats with induced cellular edema consumed significantly less food
(Fig. 1A), drank less water (Fig. 1B) and produced less solid excrements (Fig. 1C) than the controls. Urine output in rats of both groups was not significantly different (Fig. 1D).

Figure 2 shows show that there was no significant difference between the initial $(\mathrm{Ci})$ and the final (Cf) body weight in the control group (C), but in rats with $\mathrm{CE}$-induction the final weight was significantly lower (CEf) $48 \mathrm{~h}$ after the beginning of CE induction. The decrease of body weight in rats with cerebral edema was $12.3 \%$.

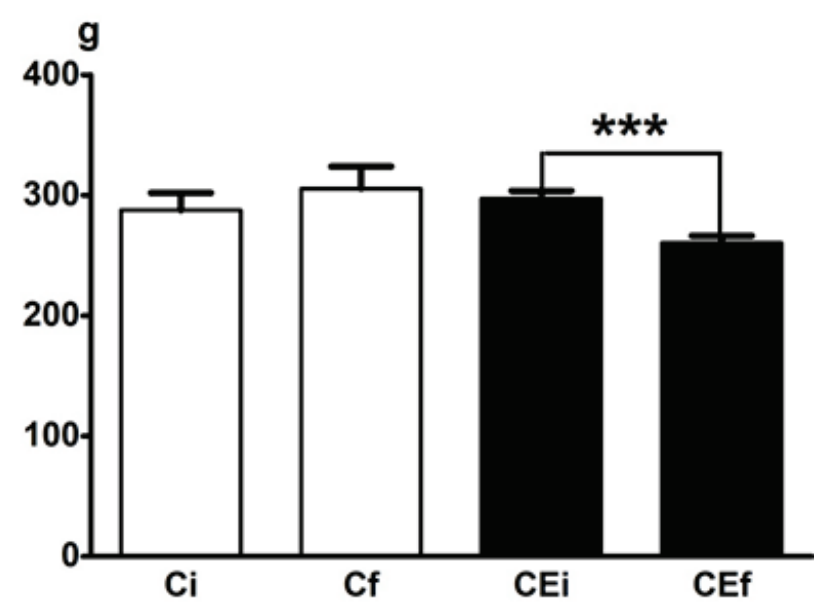

Fig. 2. The initial (i) and final ( $f$ ) body weights ( $g$ ) in the control group ( $C$, white columns) and in the group of rats with cellular edema ( $C E$, black columns). Data are means \pm SEM, significant difference between $C$ and CE groups is indicated as $* * * p<0.001$. 
Our data show that animals with cerebral edema induced by water intoxication (CE group) lost $12.3 \%$ of their body weight within $48 \mathrm{~h}$. It correlates with significantly lower food intake. Significantly lower delivery of solid excrements in CE-induced animals is associated with their low food intake. These animals were also significantly less drinking. This can be explained by the loss of thirst accompanying the water intoxication. Changes of thirst can be undoubtedly associated with the effect of antidiuretic hormone (desmopressin), which potentiates water intoxication and induces plasma dilution hyponatremia (Sterns 2015). This is a basic prerequisite for cell swelling during the induction of experimental cellular brain edema (Liang et al. 2007, Stokum et al. 2016). This experimental model shares its pathophysiological mechanisms with the clinical syndrome of inadequate ADH secretion (SIADH), which is also characterized by dilutional hyponatremia (Schwartz et al. 1957, Matsuyama et al. 2014). Plasma sodium concentration in rats with water intoxication was, on average, $20 \mathrm{mmol} / \mathrm{l}$ lower than that in rats of the control group, reflecting a significant degree of water intoxication (Kozler and Pokorný 2003). Since it is at the same time a hypervolemic state, constant urinary excretion is maintained (Wong and Verbalis 2001, Palm et al. 2001). That is why there is no significant difference in the urine output in rats of both groups.

It is possible to conclude from the results of our study that there is a direct relationship between body weight loss and reduced dietary intake of rats with cellular edema. In our previous studies, we have demonstrated that the described method of water intoxication actually induces cellular brain edema. There was increased intracranial pressure (Kozler et al. 2017a), computer tomography revealed lower brain density compared to normal brain parenchyma (Kozler and Pokorný 2014), and according to dry/wet weight ratio the water content in the brain was also higher in rats with cellular edema (Kozler et al. 2013). Other behavioral studies have shown that rats with induced cellular edema have decreased spontaneous locomotor activity (Kozler et al. 2017b, Kozler et al. 2017c). Low spontaneous physical activity can be one of the factors reducing the food intake. It corresponds with the generally inhibiting effect of CE on the brain activity (Liang et al. 2007, Inoue et al. 2013).

Our study has shown that the widely used method of water intoxication in experimental models with induced cellular edema in rats leads to a significant loss of body weight. This regularly occuring phenomenon has not yet been reported.

\section{Conflict of Interest}

There is no conflict of interest.

\section{Acknowledgements}

The work was supported by Q35/LF 1 grant.

\section{References}

AYATA C, ROPPER AH: Ischaemic brain oedema. J Clin Neurosci 9: 113-124, 2002.

INOUE T, LIN A, MA X, MCKENNA SL, CREASEY GH, MANLEY GT: Combined SCI and TBI: recovery of forelimb function after unilateral cervical spinal cord injury (SCI) is retarded by contralateral traumatic brain injury (TBI), and ipsilateral TBI balances the effects of SCI on paw placement. Exp Neurol 248: 136-147, 2013.

KIMELBERG HK: Current concepts of brain edema. Review of laboratory investigations. J Neurosurg 83: 1051-1059, 1995.

KIMELBERG HK: Water homeostasis in the brain: basic concepts. Neuroscience 129: 851-860, 2004.

KOZLER P, POKORNÝ J: Altered blood-brain barrier permeability and its effect on the distribution of Evans blue and sodium fluorescein in the rat brain applied by intracarotid injection. Physiol Res 52: 607-614, 2003.

KOZLER P, POKORNÝ J: Effect of methylprednisolone on the axonal impairment accompanying cellular brain oedema induced by water intoxication in rats. Neuro Endocrinol Lett 33: 782-786, 2012.

KOZLER P, POKORNÝ J: CT density decrease in water intoxication rat model of brain oedema. Neuro Endocrinol Lett 35: 608-612, 2014.

KOZLER P, RILJAK V, POKORNÝ J: Both water intoxication and osmotic BBB disruption increase brain water content in rats. Physiol Res 62 (Suppl 1): S75-S80, 2013. 
KOZLER P, MAREŠOVÁ D, POKORNÝ J: Methylprednisolene modulates intracranial pressure in the brain cellular edema induced by water intoxication. Physiol Res 66 (Suppl 4): S511-S516, $2017 \mathrm{a}$.

KOZLER P, MAREŠOVÁ D, POKORNÝ J: An experimental model of the "dual diagnosis": Effect of cytotoxic brain edema plus peripheral neuropathy on the spontaneous locomotor activity of rats. Neuro Endocrinol Lett 38: 101-107, 2017b.

KOZLER P, MAREŠOVÁ D, POKORNÝ J: Study of locomotion, rearing and grooming activity after single and/or concomitant lesions of central and peripheral nervous system in rats. Neuro Endocrinol Lett 38: 495-501, $2017 \mathrm{c}$.

LIANG D, BHATTA S, GERZANICH V, SIMARD JM: Cytotoxic edema: mechanisms of pathological cell swelling. Neurosurg Focus 15: E2, 2007.

MANLEY GT, FUJIMURA M, MA T, NOSHITA N, FILIZ F, BOLLEN AW, CHAN P, VERKMAN AS: Aquaporin4 deletion in mice reduces brain edema after acute water intoxication and ischemic stroke. Nat Med 6: 159-163, 2000.

MAREŠOVÁ D, KOZLER P, POKORNÝ J: Neuronal excitability after water intoxication in young rats. Neuro Endocrinol Lett 35: 274-279, 2014.

MARMAROU A: A review of progress in understanding the pathophysiology and treatment of brain edema. Neurosurg Focus 15: E1, 2007.

MATSUYAMA J, IKEDA H, SATO S, YAMAMOTO K, OHASHI G, WATANABE K: Early water intake restriction to prevent inappropriate antidiuretic hormone secretion following transsphenoidal surgery: low BMI predicts postoperative SIADH. Eur J Endocrinol 171: 711-716, 2014.

OZTAŞ B, KOÇAK H, ONER P, KÜÇÜK M: Sex-dependent changes in blood-brain barrier permeability and brain $\mathrm{Na}^{+}, \mathrm{K}^{+}$-ATPase activity in rats following acute water intoxication. $J$ Neurosci Res 62: 750-753, 2000.

PALM C, REIMANN D, GROSS P: The role of $\mathrm{V}_{2}$ vasopressin antagonists in hyponatremia. Cardiovasc Res 51: 403-408, 2001.

PAPADOPOULOS MC, VERKMAN AS: Aquaporin-4 and brain edema. Pediatr Nephrol 22: 778-784, 2007.

PLANGGER C, VÖLKL H: Effect of furosemide, bumetanide and mannitol on intracranial pressure in experimental brain edema of the rat. Zentralbl Neurochir 50: 142-144, 1989.

RHONEY DH, PARKER D, JR: Considerations in fluids and electrolytes after traumatic brain injury. Nutr Clin Pract 21: 462-478, 2006.

SCHWARTZ WB, BENNETT W, CURELOP S, BARTTER FC: A syndrome of renal sodium loss and hyponatremia probably resulting from inappropriate secretion of antidiuretic hormone. Am J Med 23: 529-542, 1957.

SILVER SM, SCHROEDER BM, BERNSTEIN P, STERNS RH: Brain adaptation to acute hyponatremia in young rats. Am J Physiol 276: R1595-R1599, 1999.

STERNS RH: Disorders of plasma sodium - causes, consequences, and correction. N Engl J Med 372: 55-65, 2015.

STOKUM JA, GERZANICH V, SIMARD JM: Molecular pathophysiology of cerebral edema. J Cerebr Blood Flow Metab 36: 513-538, 2016.

WASTERLAIN CG, POSNER JB: Cerebral edema in water intoxication. I. Clinical and chemical observations. Arch Neurol19: 71-78, 1968.

WONG LL, VERBALIS JG: Vasopressin V 2 receptors antagonists. Cardiovas Res 51: 391-402, 2001.

YAMAGUCHI M, WU S, EHARA K, NAGASHIMA T, TAMAKI N: Cerebral blood flow of rats with waterintoxicated brain edema. Acta Neurochir Suppl 60: 190-192, 1994.

YAMAGUCHI M, YAMADA T, KINOSHITA I, WU S, NAGASHIMA T, TAMAKI N: Impaired learning of active avoidance in water-intoxicated rats. Acta Neurochir Suppl 70: 152-154, 1997. 